\title{
Cervical Dislocation
}

National Cancer Institute

\section{Source}

National Cancer Institute. Cervical Dislocation. NCI Thesaurus. Code C90371.

A method of euthanization whereby the spinal column is dislocated from the skull and brain. 